\title{
Aspects regarding explosion risk assessment
}

\author{
Mihaela Părăian ${ }^{1, *}$, Sorin Burian ${ }^{1}$, Mihai Magyari ${ }^{1}$, and Lucian Moldovan ${ }^{1}$ \\ ${ }^{1}$ National Institute for Research and Development in Mine Safety and Protection to Explosion - \\ INSEMEX Petroşani, 32-34 G-ral Vasile Milea Street, 332047, Petroşani, Romania
}

\begin{abstract}
Explosive risk occurs in all activities involving flammable substances in the form of gases, vapors, mists or dusts which, in mixture with air, can generate an explosive atmosphere. As explosions can cause human losses and huge material damage, the assessment of the explosion risk and the establishment of appropriate measures to reduce it to acceptable levels according to the standards and standards in force is of particular importance for the safety and health of people and goods. There is no yet a recognized method of assessing the explosion risk, but regardless of the applied method, the likelihood of an explosive atmosphere occurrence has to be determined, together with the occurrence of an efficient ignition source and the magnitude of foreseeable consequences. In assessment processes, consequences analysis has a secondary importance since it's likely that explosions would always involve considerable damage, starting from important material damages and up to human damages that could lead to death. The purpose of the work is to highlight the important principles and elements to be taken into account for a specific risk assessment. An essential element in assessing the risk of explosion in workplaces where explosive atmospheres may occur is technical installations and personal protective equipment (PPE) that must be designed, manufactured, installed and maintained so that they cannot generate a source of ignition. Explosion prevention and protection requirements are governed by specific norms and standards, and a main part of the explosion risk assessment is related to the assessment of the compliance of the equipment / installation with these requirements.
\end{abstract}

\section{Introduction}

An essential element in assessing the risk of explosion in workplaces where explosive atmospheres may occur are facilities which must be designed, installed and maintained so as to keep flammable substances in the enclosed site to prevent the formation of explosive atmospheres around them and not to generate sources of ignition.

SR EN 15198 defines the ignition risk as the probability of occurrence of an ignition source that is capable of igniting an explosive atmosphere [1].

Explosion risk may be defined as probability of occurrence of an explosive atmosphere simultaneously with occurrence of an efficient potential ignition source and the effects induced by it [2].

* Corresponding author: mihaela.paraian@insemex.ro 


\section{Explosion risk identification and assessment}

In conformity with the requirements of the European Directive 1999/92/CE, harmonized in Romanian legislation by Government Decision no. 1058 of 9th August 2006 [3], regarding the minimum requirements for improving health safety and protection of workers which can be exposed to risks due to explosive atmospheres, the employer responsible for the workplace, according to legislation, shall coordinate application of all precautions related to workers health and safety and he has to declare in the document regarding explosion protection, the purpose of coordination. the implemented measures and procedures that had bed adopted.

When setting out the appropriate technical and organizing measures to ensure workers safety and health by the employer, several fundamental principles have to be taken into consideration, as the following ones: preventing formation of explosive atmospheres, avoiding ignition of explosive atmospheres and limiting the damaging effects of explosions.

In order to fulfil the obligations provided by the European Directive 1999/92/EC, the employer has to ensure drawing up and update of a document called Explosion protection document.

According to the guide of good practice for implementing the 1999/92/CE directive, the structure of the explosion protection document comprises a description of the workplace and work areas with explosion hazards, as well as a description of technological process stages or activities, a description of safety substances / parameters used, the risk analysis results, the explosion protective measures adopted and the implementation of explosion protection measures.

In regard to explosion risk assessment, this stage focuses initially on formation of dangerous environments, and farther on ignition sources presence and activation.

In assessment processes, consequences analysis has a secondary importance since it's likely that explosions would always involve considerable damage, starting from important material damages and up to human damages that could lead to death. The quantitative risk approach is also secondary, in explosion protection, in relation to preventing formation of dangerous explosive environments.

Each work process as well as each operating condition of an installation and each alteration of such conditions shall be subject to assessment. During new or existing installation assessment the following operating conditions shall be taken into attention: normal operation including maintenance, starting and shutting down operations, operation accidents and foreseeable malfunctions, inappropriate use that can reasonably be foreseen.

Methods for assessment of explosion risks

The concept of explosion risk consists of two elements: firstly, the probability that an explosion will occur (explosion sensitivity); and secondly, the adverse effects resulting from the occurrence of an explosion (explosion severity).

\section{Explosion Sensitivity}

Given the presence of a combustible or explosive mixture in a certain space, the probability relates to the ease of ignition.

\section{Explosion Severity}

The adverse effects of explosions relate to the amount of energy released and the time required to release this amount of energy (power), as well as to its volume density (energy/volume) and the maximum explosion temperature reached. Example of estimation and assessment of explosion risk [4]

For estimation and assessment of explosion risk must be determined two elements: severity of possible negative events and likelihood of occurrence of such events (sensitivity). Severity or consequence of explosions can many times be correctly assessed, but likelihood of occurrence is usually more difficult to quantify. 
Severity can be expressed as a pre-defined level, one or more levels that may result from each dangerous event. Thus, in terms of person or material damages in the system, severity may be expressed as follows: catastrophic, major, minor, negligible. In order to assess frequency of each severity level, as a first step the screening technique can be applied for determination of each event separate likelihood. The occurrence frequency can be expressed quantitatively as: frequent, probable, occasional, less probable, improbable.

Definitions of severity and frequency levels are given below:

$\begin{array}{lll}\Rightarrow & \text { risk level A: } & \text { High risk level } \\ \Rightarrow & \text { risk level B: } & \\ \partial & \text { risk level C: } & \\ \Rightarrow & \text { risk level D: } & \text { Low risk }\end{array}$

Table 1. Levels of severity of the identified risks

\begin{tabular}{|l|c|}
\hline SEVERITY & The definition of adverse event \\
\hline Catastrophic & Death and destruction system \\
\hline Major & Severe injury, severe illness or major system damage \\
\hline Minor & Minor injury, minor illness or minor system damage \\
\hline Negligible & Less than minor injury, illness or damage to system \\
\hline
\end{tabular}

Table 2. The frequency of risk

\begin{tabular}{|l|l|l|}
\hline $\begin{array}{l}\text { Frequency of } \\
\text { occurrence }\end{array}$ & \multicolumn{1}{|c|}{ Individual specific element } & \multicolumn{1}{|c|}{ Particularization } \\
\hline Frequent & Likely to occur frequently & It happens continuously \\
\hline Probably & $\begin{array}{l}\text { Will appear several times over the life } \\
\text { of an item }\end{array}$ & Will appear frequently \\
\hline Occasionally & $\begin{array}{l}\text { Likely to occur sometime in the life of } \\
\text { an item }\end{array}$ & Will appear several times \\
\hline Little probably & $\begin{array}{l}\text { Unlikely but possible to occur over } \\
\text { the life of an item }\end{array}$ & $\begin{array}{l}\text { Unlikely but it is reasonable to } \\
\text { expect that there }\end{array}$ \\
\hline Unlikely & $\begin{array}{l}\text { So unlikely that it can be estimated } \\
\text { that there will appear }\end{array}$ & Unlikely to occur but possible \\
\hline
\end{tabular}

Table 3. Matrix frequency /severity of risk levels

\begin{tabular}{|l|c|r|r|c|}
\hline \multirow{2}{*}{$\begin{array}{c}\text { FREQUENCY OF } \\
\text { OCCURRENCE }\end{array}$} & \multicolumn{4}{c|}{ SEVERITY } \\
\cline { 2 - 5 } & Catastrophic & Major & Minor & Negligible \\
\hline Frequent & A & A & A & C \\
\hline Probably & A & A & B & C \\
\hline Occasionally & A & B & B & D \\
\hline Less probably & A & B & C & D \\
\hline Unlikely & B & C & C & D \\
\hline
\end{tabular}

After risk estimation, the risk assessment should be performed to determine if it is necessary to reduce the risk or has reached the level of security.

It is obvious that if the risk estimate is obtained a level of risk $\mathrm{A}$, then the risk is so high that it is intolerable and additional measures are required to reduce further risks. Similarly, the risk level D can be considered acceptable and no further action is needed to reduce risk.

Thus, the risk can be described as:

Intolerable If the risk falls into this category, then you have taken appropriate security measures to reduce the risk; or: 
Acceptable If the risk falls into this category then it is necessary to reduce the risk and the risk assessment is complete.

Risk levels $\mathrm{B}$ and $\mathrm{C}$ are intermediate and normally will require risk mitigation measures to make acceptable level of risk. However, the magnitude of these measures will be lower if the risk level $\mathrm{C}$ usually organizational risk reduction measures will suffice.

Table 4. Matrix risk levels/actions

\begin{tabular}{|l|l|l|}
\hline A & High risk (intolerable) & \multicolumn{1}{|c|}{$\begin{array}{c}\text { Adequate actions, organizing and/or technical, with } \\
\text { priority }\end{array}$} \\
\hline B & Medium risk & $\begin{array}{l}\text { Adequate actions, organizing and/or technical, on short or } \\
\text { medium term }\end{array}$ \\
\hline C & Low risk & Maintains the present safety state \\
\hline D & Null risk (acceptable) & No action \\
\hline
\end{tabular}

\section{Risk assessment}

An essential element in assessing the risk of explosion in workplaces where explosive atmospheres may occur are facilities which must be designed, installed and maintained so as to keep flammable substances in the enclosed site to prevent the formation of explosive atmospheres around them and not to generate sources of ignition. They must be designed, manufactured, installed and maintained in accordance with explosion protection requirements and standards established by specific normes and standards, and a main part of the explosion risk assessment relates to the assessment of the conformity of the equipment / installation with those requirements.

The assessment has to determine if a potential ignition source may be present and to identify if an explosive atmosphere is present. The assessment begins usually by analysing the equipment during normal operation, and then is extended to take into consideration the foreseeable and rare malfunctions, in order to establish the level of explosion safety. An assessment of the likelihood of occurrence of an ignition source and its efficiency in igniting the explosive atmosphere; this requires detailed information on the flammability and explosion characteristics of the explosive atmosphere. Practically, first the areas where the explosive atmosphere may occur shall be defined, as well as the likelihood of its occurrence by applying a "Zoning" method; then the possible ignition sources shall be identified, taking into account normal operation conditions and the foreseeable and rare malfunctions [2].

In regard to equipment, protective systems and components in installation and all safety devices placed outside the explosive atmosphere but having a role of controlling the equipment safety within the Ex zones under the ATEX Directive's scope[5], the problem is sort of solved already, since these, before being placed on the market, had already been assessed by the manufacturer and are guaranteed for certain fields of use (the intended use).

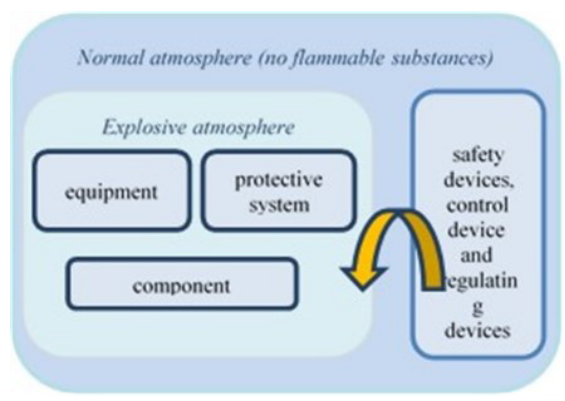

Fig. 1. Aplication domain of European Directive ATEX 2014/34/UE 
The users have only to classify their dangerous areas and then adequately choose the equipment, according to the table 5[3,5-6].

Table 5. Level of protection required, in function of the explosive atmosphere

\begin{tabular}{|c|c|c|c|c|c|}
\hline ZONE & $\begin{array}{l}\text { Presence of an explosive } \\
\text { atmosphere }\end{array}$ & $\begin{array}{l}\text { Ignition sources } \\
\text { avoidance }\end{array}$ & $\begin{array}{c}\text { Level of } \\
\text { protection } \\
\text { required }\end{array}$ & \begin{tabular}{|l|} 
Group II \\
category
\end{tabular} & EPL \\
\hline 2 & $\begin{array}{c}\text { Infrequent or only on a short } \\
\text { period of time }\end{array}$ & during normal operation & NORMAL & $3 \mathrm{G}$ & $\mathrm{Gc}$ \\
\hline 1 & Likely to occur & $\begin{array}{l}\text { also during foreseeable } \\
\text { malfunctions (one defect) }\end{array}$ & $\mathrm{HIGH}$ & $2 \mathrm{G}$ & $\mathrm{Gb}$ \\
\hline $\mathbf{0}$ & $\begin{array}{l}\text { Continuously, for long } \\
\text { periods of time } \\
\text { or frequently }\end{array}$ & $\begin{array}{c}\text { also during rare } \\
\text { malfunctions (two defects } \\
\text { independent) }\end{array}$ & $\begin{array}{l}\text { VERY } \\
\text { HIGH }\end{array}$ & $1 \mathrm{G}$ & $\mathrm{Ga}$ \\
\hline & $\begin{array}{c}\text { USERS } \\
\text { Directive1999/92/EC } \\
\text { (HG 1058/2006) }\end{array}$ & \multicolumn{4}{|c|}{$\begin{array}{c}\text { MANUFACTURERS } \\
\text { European Directive 2014/34/UE } \\
\text { (HG 245/2016) }\end{array}$} \\
\hline
\end{tabular}

Following, the installation as a whole shall be assessed in regard to possible ignition sources.

All electric and non electric equipment, as well as the associated connected devices shall be taken into consideration.

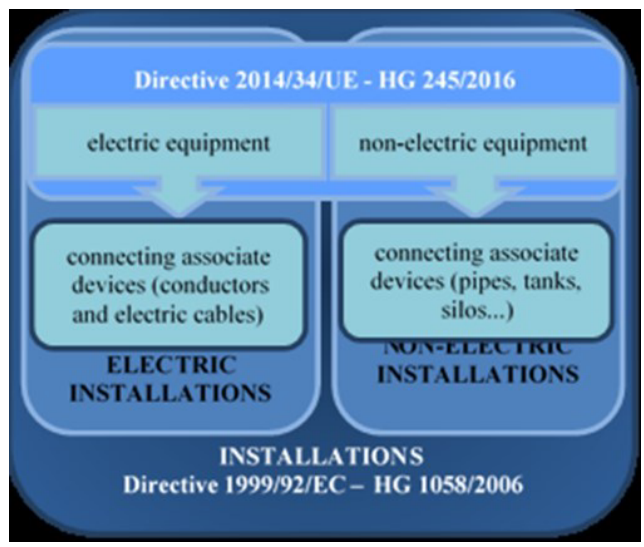

Fig. 2. Analysis of installation as a whole

Each ignition source according to EN 1127-1:2011[7] must be analyzed.

Table 6. Ignition sources according to

\begin{tabular}{|l|l|}
\hline \multicolumn{1}{|c|}{ Possible } & Reason \\
\hline \multicolumn{1}{|c|}{ Ignition sources } & \\
\hline Flames and hot gases (including hot particles) & \\
\hline Mechanically generated sparks & \\
\hline Electrical apparatus & \\
\hline Stray electric currents, cathodic corrosion protection & \\
\hline $\begin{array}{l}\text { Static electricity: Spark discharges; Corona discharges; Brush discharges; } \\
\text { Propagating brush discharges; Cone discharges }\end{array}$ & \\
\hline Lightning & \\
\hline Electromagnetic fields in the frequency range from $10^{4} \mathrm{~Hz}$ to $3 \times 10^{12} \mathrm{~Hz}$ & \\
\hline Electromagnetic radiation, frequency range from $3 \times 10^{11} \mathrm{~Hz}$ to $3 \times 10^{15} \mathrm{~Hz}$ & \\
\hline Ionizing radiation & \\
\hline
\end{tabular}




\begin{tabular}{|l|l|}
\hline \multicolumn{1}{|c|}{ Possible } & Reason \\
\hline \multicolumn{2}{|c|}{ Ignition sources } \\
\hline Ultrasonics Ex Classification: Zone1 and Zone 2 \\
\hline Adiabatic compression and shock waves, gas flows \\
\hline Chemical reactions - Exothermic reactions, including self-ignition of dusts \\
\hline \multicolumn{2}{|c|}{ Exere the potential ignition source is } \\
\hline $\begin{array}{l}\text { The equivalent level of protection corresponds to the zone where the } \\
\text { identified. }\end{array}$ \\
\hline
\end{tabular}

If is not possible to avoid explosive atmospheres and sources of ignition, protective systems should be used to limit the effects of an explosion to an acceptable extent.

When using PCE (process control engineering - PCE) to prevent the occurrence of hazardous explosive atmospheres, ignition sources or to mitigate the harmful effects of an explosion, the reliability of the safety function of PCE devices and their components must be assessed.

The risk assessment shall take into consideration also the personal protective equipment and the floorings that have an important role in prevention of dangerous static discharges from persons, which could lead to ignition of explosive atmospheres [8]. Persons insulated towards earth may easily acquire and build up electrostatic charges.

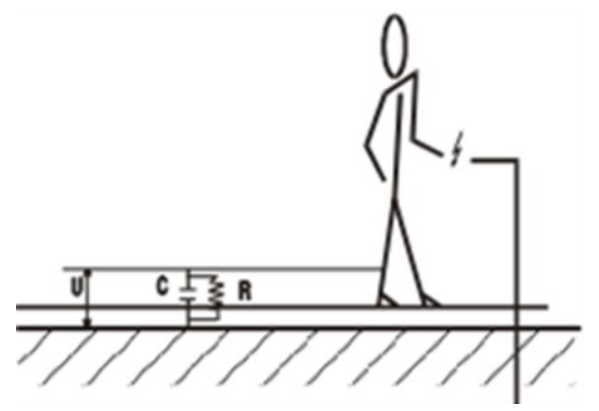

Fig. 3. Electrostatic charging of persons

In order to mitigate explosion risks, installations inspection and maintenance have also an important role.

\section{Explosion protection - the actors}

The personnel with attributions and responsibilities in the field of explosion protection and prevention: not only the competency of personnel involved in explosion risk assessment is of importance in order to mitigate explosion risk but also all the persons having attributions and responsibilities in the field of explosion protection and prevention: equipment manufacturers and users, personnel implied in repairing, service and inspection activities, as well as the control and assessment third-party bodies, named in the regulating legislation (INCD-INSEMEX, Territorial Labor Inspection bodies).

According the normative NEx 01-06/2007 at commissioning of a technical installation operating in potentially explosive atmospheres a verification of the technical documentation and an on-site assessment must be performed by INSEMEX Petrosani [9]. This is to assess the technical installation in order to check if all the measures required to ensure the protection to explosion are adopted, especially those regarding the equipment/protective systems used in Ex classified areas. Also, the legal entities engaged in the design, installation, maintenance and / or repair of technical installations operating in potentially explosive atmospheres, for carrying out specific activities must possess trained personnel 
(by INSEMEX) and have procedures / work instructions for specific activities for technical installations that operate in potentially explosive atmospheres . Also, INSEMEX can assess the capability of the organizations to perform specific activities related to technical installations operating in potentially explosive atmospheres.

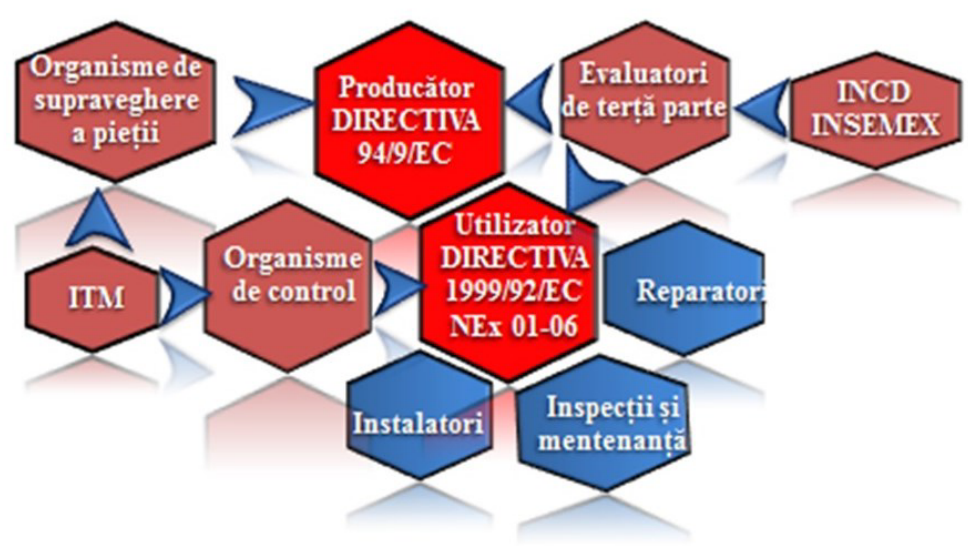

Fig. 4. Correlation between the actors having a role in explosion protection

\section{Conclusion}

Assessment of explosion risks presumes determination of the likelihood of an explosive atmosphere occurrence, together with the occurrence of an efficient ignition source and the magnitude of foreseeable consequences. In assessment processes, consequences analysis has a secondary importance since it's likely that explosions would always involve considerable damage, starting from important material damages and up to human damages that could lead to death.

The explosion risk assessment methods have to start by classifying the Ex dangerous areas, then verifying the appropriate selection of equipment and protective systems, followed by an analysis of the installation as a whole, from the possible ignition sources standpoint. Risk / safety level assessment shall relate to the safety requirements provided in the norms and standards in the field, whilst there is a presumption of ensuring a low, acceptable level of risk level, by conforming to norms.

The risk assessment shall take into consideration also the personal protective equipment and the floorings that have an important role in prevention of dangerous static discharges from persons, which could lead to ignition of explosive atmospheres.

Setting out competencies and responsibilities for those involved in installing, maintaining and inspecting installations has a particular importance for the purpose of ensuring safety against explosions.

\section{References}

1. 1.SR EN 15198: 2008 Methodology for the risk assessment of non-electrical equipment and components for intended use in potentially explosive atmospheres (2008)

2. M. Părăian, G.A.Găman, E. Ghicioi, S. Burian, F. Paun, Buletinul Institutului Politehnic din Iaşi, Tomul LV (LIX), Fasc. 1, 138-144 (2009) 
3. HG. $1058 / 2006$ sets out the minimum requirements for improving the health and safety protection of workers potentially at risk from explosive atmospheres (Directive 1999/92/CE) /Non-binding guide to good practice for implementing Directive 1999/92/EC "ATEX" (explosive atmospheres)

4. Methodology for the Risk Assessment of Unit Operations and Equipment for Use in Potentially Explosive Atmospheres, EU Project No: SMT4-CT97-2169

5. $* * *$ Directive 2014/34/EU on the harmonisation of the laws of the Member States relating to equipment and protective systems intended for use in potentially explosive atmospheres (recast), Official Journal of the European Union, 96 (2014)

6. SR EN 60079-14: 2014 Explosive atmospheres - Part 14: Electrical installations design, selection and erection, ASRO (2014)

7. SR EN 1127-1: 2008 Explosive atmospheres - Explosion prevention and protection - Part 1: Basic concepts and methodology (2008)

8. CEN/CLC/TR 16832:2015 Selection, use, care and maintenance of personal protective equipment for preventing electrostatic risks in hazardous areas (explosion risks) (2015)

9. $* * *$ Normative NEx $01-06 / 2007$, Normative of 2 may 2007 regarding explosion prevention for designing, installing, commissioning, using, repairing and maintenance of technical installations operating in potentially explosive atmospheres 